\title{
Preface
}

\section{Sam Willner}

W e have the pleasure to welcome guest editor Professor Patrice Bourdelais from EHESS, Paris, to introduce this thematic issue of Hygiea Internationalis, mainly focusing on cultural aspects of public health history. The issue is based on selected articles presented at an international conference, Cultural History of Health and Beyond, held in Paris in September 2005. We would like to express our sincere thanks to Professor Bourdelais and all contributors to this interesting volume.

We will also invite our readers to submit articles dealing with the history of public health to coming issues of Hygiea Internationalis. 
